\title{
PSICOLOGIA E RELIGIÃO: RECURSOS PARA CONSTRUÇÃO DO CONHECIMENTO
}

\author{
PSYCHOLOGY AND RELIGION: \\ RESOURCES FOR KNOWLEDGE CONSTRUCTION
}

Marília ANCONA-LOPEZ ${ }^{1}$

\begin{abstract}
RESUMO
O desafio metodológico enfrentado pela Psicologia da Religião é o de evitar o reducionismo de uma a outra. Manter um equilíbrio entre as áreas, respeitando suas especificidades, exige uma abordagem interdisciplinar que, discutindo aproximações e distanciamentos conceituais e metodológicos, permita uma análise crítica dessa relação. o pesquisador precisa movimentar-se entre as duas perspectivas mostrando competência e capacidade para estabelecer pontes entre elas. Esse diálogo permite a aproximação a fenômenos da religião, como o da meditação. Essa prática, na exegese cristã, inclui movimentos que se aproximam das propostas do método fenomenológico utilizado em investigações psicológicas; no entanto, aproximações e diferenças entre as duas propostas salientam a necessidade de diferenciação semântica.
\end{abstract}

Palavras-chave: Psicologia da Religião, Método Fenomenológico em Psicologia e Religião, Interface Psicologia e Religião.

\section{SUMMARY}

The methodological challenge faced by the Psychology of Religion is to avoid the Reductionism. To keep a balance between the two areas, considering their singularities, it is necessary a multidisciplinary approach which, discussing conceptual and methodological approaches and differences, leads to the possibility of a critical analysis of this relation. The researcher has to move between the two perspectives, showing

(1) Dra. em Psicologia Clínica na PUC-SP - Endereço para correspondência: Rua Pamplona, 237 apto 32 - Bela Vista. CEP 01405-000, São Paulo, SP. - Telefax: (11) 2895726 - E-mail: ancona1@terra.com.br 


\begin{abstract}
competence and capacity to establish links between them. This dialogue allows approaches of phenomenon, as the meditation practice. This experience proposes movements that get closer of the phenomenological method proposals, as used in psychological investigations. Approaches and differences between meditation shown by christian exegetic and the phenomenological method in psychology, allows to emphasize the necessity of semantic differentiation.
\end{abstract}

Key words: Psichology of Religion Phenomenological method in Psychology of Religion Psychology and Religion Interface.

\section{INTRODUÇÃO}

A Psicologia da Religião estuda os fenômenos religiosos como fenômenos da cultura, constituintes do ser humano. Nesse sentido examina, entre outros temas, as práticas, crenças e experiências religiosas. Um de seus desafios metodológicos é perseguir o conhecimento traçando formas de trabalho que respeitem a especificidade do saber psicológico e a singularidade das tradições religiosas. Manter "um pé em cada campo", buscando o equilíbrio entre as duas áreas e evitando aproximações redutivas, é o desafio que o pesquisador enfrenta.

A redução nos trabalhos de Psicologia da Religião apresenta-se de duas maneiras. Quando o investigador se apropria de um tema religioso para explicá-lo a partir de uma teoria psicológica, ele reduz a religião a psicologia. Considera que os fenômenos religiosos são expressões de processos humanos iguais a quaisquer outros e os descreve sem nenhuma referência aos termos da cultura religiosa que os identifica, desacreditando, implicitamente, seus significados específicos (Paloutzian, 1996). Este reducionismo rejeita a noção de que as religiões estão presentes na sociedade como corpos de conhecimentos, crenças e valores que incidem na subjetividade humana. Radicaliza o princípio da exclusão da transcendência que diz que os psicólogos da religião não devem nem afirmar nem negar a existência independente do objeto religioso, assunto que escapa à sua competência (Wulff,1997). Além disso, parte do princípio de que é possível excluir os componentes subjetivos do fazer científico.

Quando, pelo contrário, o investigador submete as explicações psicológicas às crenças e afirmações religiosas, ele reduz a psicologia a religião. Não se ocupa mais em construir uma psicologia da religião, mas sim em fazer uma psicologia religiosa, isto é, inclui a transcendência em seus trabalhos de modo radical, organizando os fenômenos e experiências em termos e valores decorrentes da fé.

Entre essas duas posições extremadas, que inevitavelmente levam a uma distorção do objeto de estudo por ignorar suas múltiplas dimensões, a visão interdisciplinar procura caminhos que permitam construir pontes entre as áreas sem negar as diferenças entre elas.

Hardy (2001) discute a possibilidade de uma metodologia interdisciplinar em Psicologia da Religião, partindo de quatro pressupostos:

1. toda linguagem é metafórica e organiza a experiência de modo a salientar ou diminuir alguns de seus aspectos;

2. a ciência é um empreendimento humano e, portanto, submetido a influências culturais, sociais e históricas e aos valores nelas implícitos;

3. qualquer estudo defronta-se com as aderências dos investigadores a crenças e 
pressupostos, sendo impossível uma total neutralidade e uma separação entre sujeito e objeto de estudo;

4. toda ciência, conseqüentemente, é limitada e implica em alguma forma de redução, portanto os trabalhos científicos precisam envolver autocrítica e expor publicamente suas limitações.

Nesta perspectiva, aponta Hardy (2001), a Psicologia da Religião que não se quer redutiva, precisa se afastar dos radicalismos e procurar modelos para a compreensão da dimensão religiosa que sejam compatíveis com as duas áreas. Não se trata de afirmar ou negar uma realidade transcendente, mas de reconhecer a especificidade das experiências consideradas transcendentes e estudá-la seriamente nas suas particularidades. Em outras palavras, o objeto de estudo informa a metodologia e a torna específica.

Concordo com o autor quando diz que uma atuação não radical, nem redutiva, em Psicologia da Religião exige uma aproximação ao objeto de estudo esperando algo qualitativamente diferente, se comparado a outros objetos de estudo da psicologia, mesmo que haja igualdades e sobreposições significativas. Considero, também, que é necessária, simultaneamente, uma aproximação ao fenômeno que alterne pontos de vista, isto é, o pesquisador precisa se movimentar entre as perspectivas psicológicas e religiosas mostrando competência em ambas (Ancona-Lopez, 2001).

São estas condições que permitirão discutir em profundidade crescente as aproximações e diferenças entre Psicologia e Religião em interessantes percursos de ida e vinda entre as duas áreas.

\section{A CONSTRUÇÃO DO CONHECIMENTO EM PSICOLOGIA E EM RELIGIÃO}

Considero neste trabalho a possibilidade de aproximar caminhos metodológicos utilizados em estudos da Psicologia e da Religião, abordando a questão do uso da meditação por psicólogos. A análise crítica comparativa, nesse caso, permite salientar a possibilidade de apreender e compreender as experiências humanas, utilizando outros recursos que não apenas os exclusivamente racionais. Em outras palavras, o processo de comparação do método exegético utilizado na religião cristã com o método fenomenológico usado em psicologia possibilita olhar para o processo de meditação, esclarecendo a sua configuração.

O método científico clássico aponta a racionalidade como o único instrumento para a produção de conhecimento, baseada na observação e experimentação realizadas com o máximo de neutralidade, ou seja, sem a interferência da subjetividade do sujeitoinvestigador. Os vários recortes necessários para a produção científica assim concebida obrigam o experimentador a construir sebes ao redor dos inúmeros modos de estar no mundo e compreendê-lo, restringindo seu próprio potencial para experienciar, apreender e conhecer os fenômenos que o rodeiam. Criam-se espaços proibidos, considerados irracionais, inadequados ao desenvolvimento da ciência, e as religiões, com toda a sua riqueza simbólica e cultural, são colocadas nesse espaço. Como em qualquer processo repressivo, aquilo que foi reprimido começa a vazar, a manifestar-se pelas bordas, a desenhar um espaço fora da fala oficial. Assim é que abundam na área da Psicologia as formas alternativas de aproximação aos fenômenos. Entre as várias práticas oriundas de campos que não o da Psicologia, mas que aparecem aliadas a ela, encontra-se a da meditação.

O número de psicólogos que pratica a meditação, que se interessa pela mesma e que a considera um instrumento que produz um certo modo de conhecer, é significativo. Tanto em relatos de pesquisas sobre temas religiosos, quanto em autores clássicos que se dedicaram a estudos de vivências alteradas 
de consciência, como na literatura das abordagens emergentes da Psicologia, como a Psicologia Transpessoal ou a Psicossíntese, encontram-se textos que se referem ao uso da meditação em Psicologia como forma de transformação e aumento de compreensão. Já em 1978, Rogers afirmava a existência de um novo e recente interesse por sonhos, o uso de vários tipos de meditação (pág. 256). Tabone (1995), em seu livro Psicologia Transpessoal, diz: uma tendência, atualmente, se expande na prática da psicoterapia transpessoal, o emprego da meditação. Este emprego se dá na relação terapeuta/cliente ou no uso individual do terapeuta, ou mesmo do cliente (pág.119). E na obra de Arcand (1997), encontram-se referências a 61 trabalhos de pesquisas sobre os efeitos da meditação em Psicologia. Apesar desses trabalhos, no entanto, o tema ainda é pouco explorado e talvez por essa razão os psicólogos que praticam a meditação e consideram seus benefícios evitam falar desse recurso em ambientes profissionais.

Boainin (1998) diz que temas tabus despertam a curiosidade científica em psicólogos inovadores. E ao estudar Rogers aponta que este autor, em vez de se escandalizar com o que observava, procurava se aproximar dos fenômenos e compreendêlos. Acredito que essa é a atitude necessária para empreender estudos nas áreas menos exploradas pela psicologia. Já em 1994 afirmei: a observação do volume de práticas extraoficiais em nossa época exige essa problematização (Ancona-Lopez, 1994, pág 57).

Tanto o termo meditação quanto a sua prática pertencem a tradições religiosas. $O$ esforço inicial de estabelecer uma relação entre esse conceito e a área da Psicologia parte do reconhecimento de uma similaridade entre o que é chamado meditação nas religiões cristãs e os movimentos propostos pelo método fenomenológico, como apresentado inicialmente por Hüsserl e assimilado posteriormente pelas ciências humanas, entre elas a Psicologia. Similaridade que encontra uma justificativa inicial na história de Hüsserl e torna viável pensar que este pensador, filho de um pastor protestante, lançou mão, no desenvolvimento de seu trabalho científico, de conhecimentos e experiências assimilados em sua formação religiosa.

Reconhecer as aproximações não implica em transferir conceitos e práticas de um campo disciplinar para outro, mas em analisar criticamente as propostas nos dois âmbitos em diferentes níveis de profundidade e assim produzir conhecimento em Psicologia da Religião. Este modo de trabalhar possibilita, ainda, integrar de modo sistematizado conhecimentos científicos e compreensões presentes nas tradições que nos rodeiam.

\section{A EXEGESE BÍBLICA}

Os monges de Camaldoli, na Itália, dedicam-se à exegese bíblica e sua competência nessa área é reconhecida no meio religioso cristão. Periodicamente ministram cursos para formação de novos exegetas. Em um desses cursos, em 1986, Gargano fala dos movimentos necessários para a interpretação dos textos bíblicos. O primeiro deles é o da meditação.

Para ensinar aos novos exegetas o que é a meditação, Gargano apresenta a seguinte metáfora, que pertence à tradição secular rabínica.

A Torá (sagrada escritura) assemelha-se a uma linda mulher que vive escondida em um aposento do seu palácio. Ela tem um amor secreto. O homem que ela ama, e que a ama também, passa horas diante do palácio observando atentamente todos os movimentos, procurando vê-la. Ela sabe que ele está lá e por isso, às vezes, abre a janela de seu quarto, só um pouquinho. Por alguns instantes deixa entrever o seu vulto, mas logo se esconde de novo. Se houver outras pessoas diante do palácio, dificilmente conseguirão vê-la, mas ele a vê e se sente cada vez mais atraído por 
ela e tem a certeza, em seu coração, em sua alma e em todo o seu ser, que é por amor a ele que ela se mostra por uns momentos. Assim é a palavra da Torá, ela se revela apenas aos seus amantes. De início, ela deixa apenas vislumbrar sua beleza, mas, depois que ele a enxerga, ela começa a chamá-lo sutilmente. $E$, quando sabe que ele é capaz de ouvi-la, ela envia mensageiros para dizer: se você ouviu o meu murmúrio, venha para que eu possa lhe falar. Quando, finalmente, ele se aproxima dela, ela começa a falar de forma mais clara, por detrás de seus véus, acostumando-o com sua linguagem. Ela transmite palavras alegóricas, envoltas em luz. São palavras que introduzem o amado nos mistérios divinos e é somente quando ele se familiariza com essa linguagem que ela se revela face a face. Esse homem torna-se então um mestre, ou seja, o esposo da Torá, para quem ela não esconde nada, mostra todos os segredos e para quem diz: veja quanta coisa havia por detrás daquele simples sinal que eu lhe dei quando entreabri a janela. E ele compreende, então, o significado das palavras da Torá como se elas estivessem todas juntas diante dele. Palavras às quais ele não pode acrescentar ou subtrair uma única letra.

É apenas nessa relação de amor que se pode compreender a Torá, diz Gargano. O sentido que se extrai dela depende da capacidade de amá-la e o caminho que permite estabelecer essa relação de amor é o da meditação. Ela se compõe de três movimentos.

O primeiro movimento é de escuta. É no silêncio e na solidão que se pode entrever algum sentido, ou seja, perceber o murmúrio ao qual a metáfora da Torá se refere. Isto significa buscar um local exterior e interior que permita escutar as palavras e colocá-las dentro de si, mesmo sem ainda compreendê-las. É um movimento de recolhimento que permite ouvir murmúrios e guardar as palavras em seu coração para, em seguida, deixar-se abraçar pelo silêncio. É um trabalho de formiga que guarda e armazena.
O segundo movimento assemelha-se à atividade da abelha. Trata-se de retirar mel das palavras. Elas precisam ser trabalhadas, reviradas de todas as formas possíveis e com todas as técnicas ao dispor até que algumas luzes surjam. Uma palavra faz lembrar uma imagem, um personagem, um sentido etimológico, associa-se a um ou outro texto, e esse trabalho começa a dar fruto. Nessa fase da meditação é preciso deixar-se atingir pelas palavras e estabelecer com elas um encontro pessoal. Elas começam a se amalgamar entre si e a formar um sentido, para além do conhecimento pessoal, e começa a mostrar uma possibilidade de interpretação.

A terceira fase realiza o trabalho da peneira. É um trabalho de esclarecimento, em que há um confronto e um ajuste de interpretações que estabelece um contorno e desenha uma compreensão. A luz dela resultante invade a pessoa como uma espada luminosa que a atravessa totalmente. Nesse momento, para Gargano, a meditação pode transformar-se em oração assumindo diferentes formas.

Assim, na meditação, o primeiro momento é o da colheita, o segundo o do amadurecimento e o terceiro o da iluminação que tem um efeito transformador.

\section{O MÉTODO FENOMENOLÓGICO}

Hüsserl procurou estabelecer a Filosofia como uma ciência de rigor e partiu do conceito de intencionalidade mostrando a indissociabilidade da consciência e do objeto intencionais e a sua constituição unívoca. Esta unicidade resulta na participação da subjetividade do pesquisador na produção de conhecimento. Apesar de a proposta de Hüsserl incluir a afetividade nesta participação, ela se caracteriza por um racionalismo, isto é, um incessante movimento de elucidação que procura, através de uma seqüência de reduções, atingir a essência da constituição intencional. 
Essência que não é anterior à existência, mas constituída no campo intencional (Hüsserl, 1935).

A afirmação da intencionalidade como limite de conhecimento, que impede a aceitação de um mundo "em si" e substitui "real" por "fenômeno", colocou em pauta a questão dos sentidos e da interpretação. Conseqüentemente, o desenvolvimento da fenomenologia, principalmente com as contribuições de Heidegger, desembocou na discussão da hermenêutica e envolveu autores, entre os quais Bultman e Ricoeur, que consideravam em seus trabalhos as posições exegéticas e religiosas. A influência do judaísmo é evidente em Hüsserl, de tal modo que os primeiros escritos da fenomenologia são eivados de termos religiosos. Ele associa, entre outros, os efeitos da redução à conversão religiosa e a busca das essências à meditação infinita (Hüsserl, 1935). Essa influência, aliada aos questionamentos privilegiados pela fenomenologia - possibilidade de afirmar ou negar o transcendente, abertura do campo intencional, universalidade da essência, existência de um sentido, condições de interpretação -, formou um tecido propício ao diálogo da Fenomenologia com a Religião.

Em outro interessante movimento interdisciplinar, os discursos fenomenológicos desenvolvidos no âmbito da Filosofia tiveram seus efeitos na Psicologia. Embora a passagem dos conceitos de uma área para a outra nunca tenha sido claramente resolvida, é inegável a apropriação das discussões da hermenêutica pelas psicanálises e do método husserliano pelas pesquisas fenomenológicas em psicologia. O método fenomenológico, amplamente utilizado pelas correntes humanistas, pela gestalt e pelas psicologias fenomenológico-existenciais passou a ser entendido como um conjunto de movimentos que permite compreender as experiências psicológicas e construir os seus significados. É assim que o tratamos neste artigo.
As pesquisas fenomenológicas em psicologia trabalham a maior parte das vezes com relatos de experiências, orais ou escritas. A descrição da análise desses relatos pelos pesquisadores mostra procedimentos comuns. Trata-se, em primeiro lugar, de ler e reler os textos, tantas quantas forem necessárias para mergulhar nos mesmos, conhecer suas nuances, explorar as relações, os termos usados, deixar-se atingir por ele. É possível, em seguida, trabalhar o texto separando unidades de significado, agrupando-as, organizando categorias, estabelecendo um relato descritivo de seu conteúdo ou expressando-o através de uma narrativa. Atividade que, amadurecendo, permite que se organize uma figura, uma gestalt na qual os vários significados se organizam entrelaçando-se e formando um desenho que revela um dos modos possíveis de compreensão do fenômeno.

Forghieri (1993) descreve esses movimentos quando relata o seu próprio modo de trabalhar em uma de suas pesquisas: inicialmente li o relato inteiro de cada sujeito, procurando me envolver e penetrar na sua vivência, dele sentindo-me próxima... Depois, fiz uma releitura de cada um dos tipos de vivência, separadamente, de acordo com a seqüência na qual foram descritos pelo sujeito e me detive em cada parte do relato...Ao me deter, procurei envolver-me na vivência do sujeito ou nela penetrar para captar, intuitivamente, o seu significado para ele (pág. 65). Ela afirma que o pesquisador precisa abrir-se à vivência que quer conhecer, estabelecendo com ela uma profunda sintonia, ou seja, nela se envolvendo. Apenas então poderá trabalhar sobre o relato mantendo um distanciamento reflexivo. Nesse movimento, para compreendê-lo, relaciona-o à sua própria vivência e à de outras pessoas, reflete sobre tudo isto (pág. 61).

A mesma atitude é expressa por Day e Naedts (1994): quando encontramos uma pessoa em uma entrevista de pesquisa, ou temos que lidar com o texto que foi gravado 
nesse encontro estamos engajados em um processo de conversação com o texto, que é dialógico (...) Achamos melhor considerar que os textos são lidos apropriadamente quando eles são lidos responsavelmente; quando eles são lidos e relidos... (pág. 175).

\section{PROXIMIDADES E DISTANCIAMENTOS}

Em uma primeira análise, a metáfora da Torá é muito similar às propostas fenomenológicas. Dizer que o amado fica às grades do palácio observando todos os movimentos, guarda em si as palavras da Torá para depois trabalhá-las e deixar que se revelem é semelhante a dizer que o pesquisador deve ler e reler o texto atentamente, confrontá-lo com a própria vivência e trabalhá-lo reflexivamente até que ele se organize e possa ser expresso em uma narrativa. Os dois discursos, enfim, propõem um mergulho no texto, um envolvimento com o mesmo, o estabelecimento de uma relação laboriosa, dedicada e íntima.

As similaridades, no entanto, não podem ser confundidas com identidade.

Diferenças fundamentais podem ser observadas. A fenomenologia coloca o conhecimento em uma esfera intencional e afirma a impossibilidade de transcender esse espaço. O exegeta cristão fala de uma palavra que tem origem divina. Se a fenomenologia busca o conhecimento de um sentido construído na existência, para Gargano o conhecimento é o alcance de um sentido último, que é a própria razão da existência. Trata-se, portanto, de colocações originadas em diferentes contextos, escritas com objetivos diversos e que assumem pontos de partida divergentes no que diz respeito aos conceitos de mundo, de homem e de conhecimento. Os fenomenólogos ouvem um texto buscando a constituição de um fenômeno, os exegetas cristãos ouvem o texto buscando a voz de Deus. Fenomenólogos e exegetas seguem caminhos paralelos e podem obter resultados semelhantes em suas investigações, mas a diferença incidirá na interpretação e no valor atribuído aos resultados.

A análise das proximidades e diferenças entre as duas propostas permite outras considerações sobre o tema da meditação.

O caminho da meditação, como proposto por Gargano, explicita um conjunto de habilidades a serem desenvolvidas e descreve os modos de fazê-lo. Meditar significa buscar o silêncio interior, desenvolver a escuta, a atenção, o cuidado. Essas habilidades são consideradas pela psicologia, mas esta não propõe uma prática que as abarque e desenvolva. Assim, se alguns psicólogos meditam no sentido religioso, é possível que outros meditem no sentido laico, isto é, realizem uma prática que busca desenvolver recursos próprios úteis ao trabalho psicológico. Esta observação mostra a necessidade de desenvolver pesquisas que trabalhem a distinção semântica entre as áreas, facilitando a cada um delimitar com clareza o lugar de sua ação e nomear adequadamente a sua prática.

A análise comparativa possibilita, ainda, dar visibilidade aos aspectos afetivos presentes na produção do conhecimento. Gargano, coerentemente com a sua tradição cristã, anuncia a importância do amor na produção do conhecimento e, de forma poética, explicita o aspecto afetivo emocional presente na relação do exegeta com a Torá. Amor expresso na dedicação do tempo, da atenção, do interesse, da procura e que concretiza uma relação que ultrapassa aspectos meramente intelectuais. Estas qualidades estão implícitas na descrição da investigação fenomenológica, mas são menos valorizadas, já que o trabalho se desenvolve em um contexto que enfatiza, acima de tudo, a racionalidade.

No entanto, o movimento de amor apontado por Gargano pode ser reconhecido nas relações propostas para o desenvolvimento do conhecimento fenomenológico: dedicar-se ao objeto de estudo, ouvi-lo, escutá-lo, entregar a ele o seu tempo, esvaziar-se diante do 
mesmo, deixar-se afetar são termos freqüentes nos discursos sobre as práticas e pesquisas psicológicas e implicam em mobilizações de sentimentos, abertura e acolhimento do que queremos conhecer. A análise comparativa salienta a importância de acrescentar calor e afeto como componentes do trabalho de produção de conhecimento e lembra que os atos de apreender e aprender envolvem também o coração.

Afinal, Hüsserl sempre afirmou a impossibilidade de separação entre sujeito e objeto e o sujeito não pode ser pensado apenas como racionalidade. A unicidade do pesquisador com o seu objeto de estudo envolve o investigador em toda a sua subjetividade: sua razão, seu corpo e seu afeto e a "meditação" surge como possibilidade de trabalho sobre todos esses aspectos. O que seu uso nos sugere é que, talvez seja importante, em termos metodológicos, dedicar maior cuidado ao modo como nossas disposições afetivas, para não dizer "como o amor", facilitam ou dificultam, cerceiam ou potencializam nosso modo de conhecer. É nessa mobilização de afetos que podemos encontrar a forma única de compreender o mundo e contribuir de forma pessoal para o aumento do conhecimento psicológico.

\section{REFERÊNCIAS BIBLIOGRÁFICAS}

ANCONA-LOPEZ, M. (1996). Caminho de Acesso à Análise Crítica das Práticas Psicológicas Alternativas. Anais do VI Simpósio de Pesquisa e Intercâmbio Científico da ANPEPP, Teresópolis, RJ.

ANCONA-LOPEZ, M. (2001). Marisa: a psychologist's difficulties in connecting religious life with professional practice. Annual Meeting of the International Association for the Psychology of Religion - Post Conference, Maarchen, The Netherlands, 01-02 de outubro de 2001.
ARCAND, M. (1997). S'initier à la méditation. Paris, Le Jour.

BOAINAIN JR, E. (1998). Tornar-se Transpessoal: Transcendência e Espiritualidade na Obra de Carl Rogers. São Paulo, Summus Ed.

DAY, J. M. \& Naedts, M. H. L. (1997). A Reader's Guide for Interpreting Texts of Religious Experience: a Hermeneutical Approach. In J. A. Belzen (ed.) Hermeneutical Approaches in Psychology of Religion. Ed. Rodopi, Amsterdam.

FORGHIERI, Y. C. (1993). Psicologia Fenomenológica: fundamentos, método e pesquisas. São Paulo, Pioneira.

GARGANO, I. (1996). Natureza, Pressupostos e Critérios da Lectio Divina. Círculo de conferências sobre a Lectio Divina, Camaldoli, 30 junho a 5 de julho de 1986, fita gravada cedida pelas Irmãs da Consolata, São Paulo.

HARDY, D. S. (2001). Radical Reductionism in the Psychological Study of Religion: prospects for an alternative critical methodology. Annual Meeting of the International Association for the Psychology of Religion, Soesterberg, The Netherlands, 28-30 de setembro de 2001.

HÜSSERL, E. (1935/1976). La crise dés sciences européennes et la phénoménologie transcendantale. Ed. Gallimard,Paris.

PALOUTZIAN, R. F. (1996). Invitation to the psychology of religion. Boston, Allyn \& Bacon.

ROGERS, C. (1978). Sobre o poder pessoal. São Paulo, Martins Fontes.

TABONE, M. (1995). A Psicologia Transpessoal. São Paulo, Cultrix.

WULFF, D. M. (1997). Psychology of Religion: classic and contemporary. New York, John Wiley \& Sons. 